\title{
Síndrome de Burnout entre os trabalhadores da Estratégia de Saúde da Família*
}

\author{
SYNDROME OF BURNOUT AMONG THE WORKERS OF THE STRATEGY OF \\ HEALTH OF THE FAMILY \\ SÍNDROME DE BURNOUT ENTRE LOS TRABAJADORES DE LA ESTRATEGIA DE \\ SALUD DE LAFAMILIA
}

\section{Letícia de Lima Trindade ${ }^{1}$, Liana Lautert ${ }^{2}$}

\begin{abstract}
RESUMO
Trata-se de um estudo descritivo, desenvolvido junto a dezesseis equipes de Estratégia de Saúde da Família de Santa Maria (RS), que objetivou identificar os trabalhadores com a Síndrome de Burnout e as variáveis associadas a este distúrbio. A amostra foi composta por 86 trabalhadores, representando $86,3 \%$ dos profissionais (médico, enfermeiro, técnico de enfermagem, odontólogo e auxiliar de consultório dentário) e 30,2\% dos agentes comunitários de saúde, os quais responderam ao Maslach Inventory Burnout. A idade média do grupo foi de $36,94 \pm 9,3$ anos, com predominância do sexo feminino $(84,9 \%)$. A maioria possui companheiro $(68,2 \%)$, tem filhos $(69,4 \%)$, trabalha, em média, $3,38 \pm 1,9$ anos na equipe e não realiza atividades físicas $(62,8 \%)$. Identificaramse seis trabalhadores $(6,9 \%)$ com a Síndrome de Burnout, a qual teve associação estatística significativa $(p=0,034)$ com a variável idade jovem. Os mais jovens obtiveram escores superiores nas subescalas de desgaste emocional e despersonalização do Inventário de Burnout.
\end{abstract}

\section{DESCRITORES}

Enfermagem.

Estresse.

Saúde do trabalhador.

Esgotamento profissional.

Programa Saúde da Família.

\begin{abstract}
This descriptive study was developed with sixteen Family Health Strategy teams from Santa Maria (Rio Grande do Sul), with the objective to identify works with the Burnout syndrome and the variables associated with this disorder. The sample consisted of 86 workers, representing $86.3 \%$ of professionals (physicians, nurses, nursing technicians, dentists and dental office assistants) and $30.2 \%$ of community health agents, who answered the Maslach Burnout Inventory. The average age of the group was $36.94 \pm 9.3$ years, with a predominance of females (84.9\%). Most participants had a partner $(68.2 \%)$, children (69.4\%), have worked in the team for, in average, $3.38 \pm 1.9$ years and do not exercise regularly $(62.8 \%)$. Six workers (6.9\%) presented the Burnout Syndrome, which has a statistically significant association ( $p=0.034)$ with the young age variable. Younger subjects obtained higher scores on the subscales for emotional distress and depersonalitation on the Burnout Inventory.
\end{abstract}

\section{KEY WORDS \\ Nursing. \\ Stress. \\ Occupatinoal health. \\ Burnout, professional. \\ Family Health Program.}

\begin{abstract}
RESUMEN
Se trata de un estudio descriptivo, desarrollado junto a dieciséis equipos de Estrategia de la Salud de la Familia de Santa María (RS, Brasil) que tuvo como objetivo identificar a los trabajadores con el Síndrome de Burnout y las variables asociadas a este disturbio. La muestra se compuso de 86 trabajadores, que representaban el $86,3 \%$ de los profesionales (médicos, enfermeros, técnicos en enfermería, odontólogos y auxiliares de consultorio odontológico) y $30,2 \%$ de los agentes comunitarios de salud, los cuales respondieron al Maslach Inventory Burnout. La edad promedio del grupo fue de $36,94 \pm 9,3$ años, con predominancia de sexo femenino (84,9\%). La mayoría vive en pareja $(68,2 \%)$, tiene hijos $(69,4 \%)$, ha trabajado en el equipo durante un promedio de $3,38 \pm 1,9$ años y no realiza actividades físicas $(62,8 \%)$. Se identificaron seis trabajadores $(6,9 \%)$ con Síndrome de Burnout, los cuales tuvieron una asociación estadísticamente significativa con la parte más baja de la faja etaria estudiada. Los más jóvenes obtuvieron puntajes superiores en las subescalas de desgaste emocional y despersonalización del Inventario de Burnout.
\end{abstract}

\author{
DESCRIPTORES \\ Enfermería. \\ Estrés. \\ Salud laboral. \\ Agotamiento profesional. \\ Programa de Salud Familiar.
}

\footnotetext{
* Extraído da dissertação "O estresse laboral da equipe de saúde da família: implicações para Saúde do Trabalhador", Universidade Federal do Rio Grande do Sul, 2007. ${ }^{1}$ Enfermeira. Mestre em Enfermagem. Doutoranda do Programa de Pós-graduação em Enfermagem da Universidade Federal de Santa Catarina. Professora da Faculdade de Pato Branco e do Centro Universitário Católico do Sudoeste do Paraná. Pato Branco, PR, Brasil. letrindade@hotmail.com ${ }^{2}$ Enfermeira. Professora Doutora da Escola de Enfermagem da Universidade Federal do Rio Grande do Sul. Porto Alegre, RS, Brasil. ila@enf.ufrgs.br

$27 \begin{aligned} \text { Rev Esc Enferm USP } & \text { Recebido: 08/04/2008 } \\ \text { 2010; 44(2):274-9 } & \text { Aprovado: 01/06/2009 }\end{aligned}$
}




\section{INTRODUÇÃO}

As contínuas e crescentes transformações, de ordem econômica, política, social e técnica, que vêm se processando no mundo do trabalho têm exercido forte influência sobre a saúde dos trabalhadores ${ }^{(1-2)}$.

Alguns estudos ${ }^{(1-3)}$ apontam o crescimento do número de trabalhadores da área da saúde acometidos pelo adoecimento no trabalho, o que gera a necessidade de investimentos para identificar as causas destes danos e de ações que contribuam para redução destas taxas e, em conseqüência, preservem a saúde do trabalhador.

Entre os diferentes fatores que podem comprometer a saúde do trabalhador, o ambiente de trabalho é apontado como gerador de conflito quando o indivíduo percebe o hiato existente entre o compromisso com a profissão e o sistema em que estão inseridos ${ }^{(2)}$.

Neste sentido, aborda-se o contexto da Estratégia de Saúde da Família (ESF), anteriormente chamado de Programa de Saúde da Família (PSF), por propor uma mudança do modelo assistencial à saúde. A ESF objetiva reduzir a distância entre as equipes de saúde e a população e para tanto exige diferentes habilidades dos trabalhadores desta modalidade de atenção. Os membros da ESF estão em contato diário com a realidade de comunidades, as quais em geral, são carentes em múltiplos aspectos, o que pressupõe diferentes recursos e enfrentamentos ${ }^{(1-2)}$ dos trabalhadores.

O PSF surgiu em $1994^{(4)}$ e visa desenvolver atividades de prevenção de doenças e promoção da saúde por meio de ações educativas realizadas nos domicílios ou junto às coletividades, um dos principais desafios dos países subdesenvolvidos. Recebe incentivos financeiros para sua implantação em todos os Estados brasileiros e tem como princípio desenvolver estratégias que atendam as demandas da população local, valorizando seus anseios e acolhendo suas necessidades com eqüidade.

Sendo assim, acredita-se que os membros da ESF enfrentam diversos desafios para qualificar a atenção à saúde dos indivíduos e famílias sob sua responsabilidade.

Os trabalhadores inseridos nesse modelo de atenção à saúde ficam expostos à realidade destas comunidades nas quais os recursos são escassos para atender as complexas demandas com as quais se deparam. Somam-se a isto, algumas falhas na rede de atenção à saúde que se refletem no trabalho e afetam a resolutividade das ações.

Os membros da ESF também se deparam com ambientes, muitas vezes, perigosos, insalubres e propícios a riscos à saúde, o que se adiciona às pressões e exigências do pró- prio trabalho e favorece o desenvolvimento da Síndrome de Burnout e outras doenças relacionadas ao trabalho ${ }^{(5-6)}$.

A Síndrome de Burnout, conceituada como o estresse laboral crônico, caracteriza-se pelo esgotamento físico e emocional do trabalhador ${ }^{(7)}$, que ocorre quando o indivíduo não possui mais estratégias para enfrentar as situações e conflitos no trabalho.

Para os pesquisadores americanos, o estresse crônico associado ao trabalho denota Burnout, ou seja, combustão completa ${ }^{(7)}$. A Síndrome pode atingir indivíduos de diferentes categorias profissionais, em qualquer faixa etária, mas as profissões que exigem um intenso contato interpessoal são as que apresentam altos índices de trabalhadores com Burnout e, entre elas, encontram-se as profissões assistenciais ${ }^{(8)}$.

A Síndrome de Burnout é associada ao trabalho, decorre da exposição prolongada aos estressores laborais e falta de apoio social o que gera desgaste físico e psíquico do trabalhador ${ }^{(8)}$.

O Burnout é caracterizado por um conjunto de sinais e sintomas físicos e psíquicos, conseqüentes da má adaptação ao trabalho e com intensa carga emocional e pode estar acompanhado de frustração em relação a si e ao trabalho(9).

Observa-se que os trabalhadores da ESF estão expostos a diversos desafios e estressores laborais o que requer uma série de habilidades para atender à população bem como para o exercício do autocuidado. E caso não utilizem estratégias de enfrentamento adequadas, ficam vulneráveis ao Burnout. Portanto, optou-se por investigar o estresse laboral entre estes trabalhadores, uma vez que o trabaIho faz parte da suas vidas, colabora para a formação da identidade e subjetividade e é por meio dele que organizam suas vidas, participam da sociedade e desenvolvem sua visão do mundo(10).

\section{OBJETIVO}

Identificar a Síndrome de Burnout entre os profissionais que trabalham nas ESFs do Município de Santa Maria/ RS e as variáveis associadas a este distúrbio.

\section{MÉTODO}

Trata-se de uma pesquisa descritiva, com abordagem quantitativa, para identificar a Síndrome de Burnout entre os trabalhadores que atuam nas unidades da ESF, em Santa Maria/RS. Neste Município existem 16 ESFs, com equipes de trabalho que variam de tamanho, tendo no mínimo oito e no máximo doze pessoas. 
Santa Maria encontra-se na região central do Estado do Rio Grande do Sul, possui aproximadamente 270.073 habitantes, a maioria residente da zona urbana. 0 fluxo monetário do Município depende fundamentalmente do serviço público e as principais áreas produtivas são: a educacional, médico-hospitalar e militar.

Foram convidados a participar do estudo todos os 66 profissionais das ESFs do Município e penas dois agentes comunitários de saúde (ACS) de cada ESF. Isto ocorreu devido ao número elevado de ACS em cada ESF (de 6 a 8) e o tempo disponível para a pesquisa. A seleção dos agentes foi intencional, optando-se por aqueles que estavam na unidade no momento da coleta dos dados e se interessaram pela pesquisa.

Aceitaram participar do estudo 57 profissionais (86,36\%) e 29 ACSs (30,2\%), totalizando uma amostra com 86 trabalhadores.

A coleta dos dados foi realizada nos meses de janeiro e fevereiro de 2007 , sendo pré-agendada com as equipes. $\mathrm{Na}$ maioria das ocasiões, a coleta foi realizada durante as reuniões de equipe. Os instrumentos foram preenchidos individualmente e na presença da pesquisadora.

Utilizou-se como instrumento para coleta de dados um questionário auto-aplicado constituído por duas partes. $\mathrm{Na}$ parte inicial constaram questões para coleta de dados demográficos dos participantes e na segunda foi incluído o Maslach Inventory Burnout (MBI). Trata-se de, uma escala do tipo Likert sete pontos com 22 questões: nove avaliam o desgaste emocional, cinco a despersonalização e oito a realização profissional, tendo esta última subescala, o escore inverso.

O Inventário de Burnout é um dos instrumentos mais conhecidos para pesquisas com diferentes profissionais ${ }^{(11-12)}$, o qual foi traduzido para o português e validado em 1995, obtendo um alfa de Cronbach de 0,86 na subescala de desgaste emocional, 0,69 em despersonalização e 0,76 em realização profissional ${ }^{(13)}$. Para análise dos dados foi usada a estatística descritiva e o programa Statistical Package for the Social Sciences (Programa SPSS), versão 10.01 for Windows. Testou-se a associação entre as características demográficas da amostra e as três subescalas do $\mathrm{MBI}$, utilizando-se o teste de qui-quadrado para as variáveis qualitativas e o Teste $t$ de Student para as quantitativas.

O estudo teve aprovação do Comitê de Ética em Pesquisa da UFRGS (número 2006643). Após a aprovação foi realizado contato com a Secretaria de Saúde de Santa Maria para expor o projeto de pesquisa e solicitar autorização para apresentação do mesmo às equipes das ESFs. Todos os trabalhadores que aceitaram participar do estudo assinaram o Termo de Consentimento Livre e Esclarecido.

\section{RESULTADOS}

Por meio do Maslach Inventory Burnout foi possível identificar a Síndrome de Burnout entre os trabalhadores que atuam nas ESFs do Município de Santa Maria/RS e as variáveis associadas a esse distúrbio.

\section{Dados demográficos}

Cada equipe de ESF do Município é composta por, no mínimo, um médico, um enfermeiro, um técnico de enfermagem e cinco agentes comunitários de saúde (ACSs), entretanto algumas possuem também o odontólogo e o auxiliar de consultório dentário(ACD).

Ao todo 162 pessoas trabalham nas dezesseis (16) ESFs e destas, 86 aceitaram participar da pesquisa, sendo cinco odontólogos (100\%); doze médicos (74\%); treze enfermeiros (81,3\%); dezenove técnicos de enfermagem $(79,2 \%)$, oito ACDs (62,5\%) e vinte e nove ACSs (30,2\%). Entre estas, 30 (34,9\%) eram trabalhadores com formação superior; 27 $(31,4 \%)$ possuíam curso técnico; e 29 (33,7\%) concluíram o ensino médio (agentes comunitários); sendo $73(84,9 \%)$ do sexo feminino; $58(68,2 \%)$ têm companheiro e $59(69,4 \%)$ têm filhos.

A média de idade do grupo foi de $36,94 \pm 9,3$ anos, sendo a idade mínima de 20 anos e a máxima de 68 anos. Os mais jovens, ou seja, os que possuem idade até 40 anos, obtiveram escores superiores nas subescalas de desgaste emocional e despersonalização do Inventário e, inferiores em realização profissional. $A$ idade foi a única variável que obteve associação estatisticamente significativa $(p=0,034$ -Teste $t$ de Student).

A média dos anos de escolaridade entre os trabalhadores foi de $14,4 \pm 4,9$, o tempo mínimo e máximo foi de 11 e 35 anos, respectivamente e não houve associação entre esta variável e as subescalas do $\mathrm{MBI}$.

O tempo de trabalho na ESF foi de $3,38 \pm 1,9$ anos, a mediana de 34,5 meses, o mínimo foi de um mês e o máximo de 108 meses ( 9 anos); $25 \%$ dos sujeitos atuam há 28 meses ( 2,3 anos) na ESF; $50 \%$ há 34 meses (2,8 anos) e $75 \%$ há 52 meses (4,3 anos). Estes dados coincidiram com o tempo na profissão que foi no mínimo de 10 meses e no máximo de 41 anos, com média de 3,69 22,29 anos. Entre os trabalhadores, $25 \%$ tinham até dois anos na profissão, $50 \%$ até três anos e $75 \%$ até seis anos.

Quanto ao vínculo empregatício, a maioria dos trabaIhadores $(67,4 \%)$ trabalha somente na ESF; entretanto, um percentual representativo $(32,6 \%)$, referiu trabalhar em outro local.

Os trabalhadores revelaram que a atividade extra laboral mais praticada é a de afazeres domésticos, referida por 68 trabalhadores $(79,1 \%)$, dado que pode ser explicado pela amostra predominantemente feminina $(84,9 \%)$. As outras atividades extra laborais estão relacionadas ao lazer: $67,4 \%$ assiste televisão e $60,5 \%$ realiza leitura de jornais, livros, revistas e 53,5\% estuda. A realização de exercícios físicos foi assinalada por $32(37,2 \%)$ trabalhadores. Tanto as atividades extra laborais como trabalhar em outro local, não tiveram associação estatística 
com os escores do Inventário de Burnout. Também não houve associação estatística entre os escores das três subescalas do $\mathrm{MBI}$ e as variáveis: sexo, tempo de serviço na profissão, categoria profissional, estado civil, ter filhos, anos de estudo e equipe em que trabalha e tempo de serviço no ESF.

\section{Dados do Inventário de Burnout}

As médias dos escores dos trabalhadores da ESF nas três subescalas do $\mathrm{MBI}$ foram respectivamente: 9,0 $\pm 3,05 \mathrm{em}$ Despersonalização, 23,87 $\pm 7,19$ em Desgaste Emocional e $13,84 \pm 4,82$ em Realização profissional.
Os trabalhadores acometidos pela Síndrome de Burnout foram aqueles que obtiveram escore com um desvio padrão acima da média do grupo nas subescalas desgaste emocional e despersonalização e um desvio padrão abaixo da média em realização profissional (escala reversa), os quais foram denominados de desgastados. Estes compuseram um grupo com seis pessoas, sendo três ACSs, dois técnicos de enfermagem e um médico, todos do sexo feminino, com idades de $21,27,28,29,30$ e 40 anos e pertencentes a diferentes unidades da ESF.

Na Figura 1 são apresentados os escores médios dos trabalhadores da ESF e do grupo com Burnout.

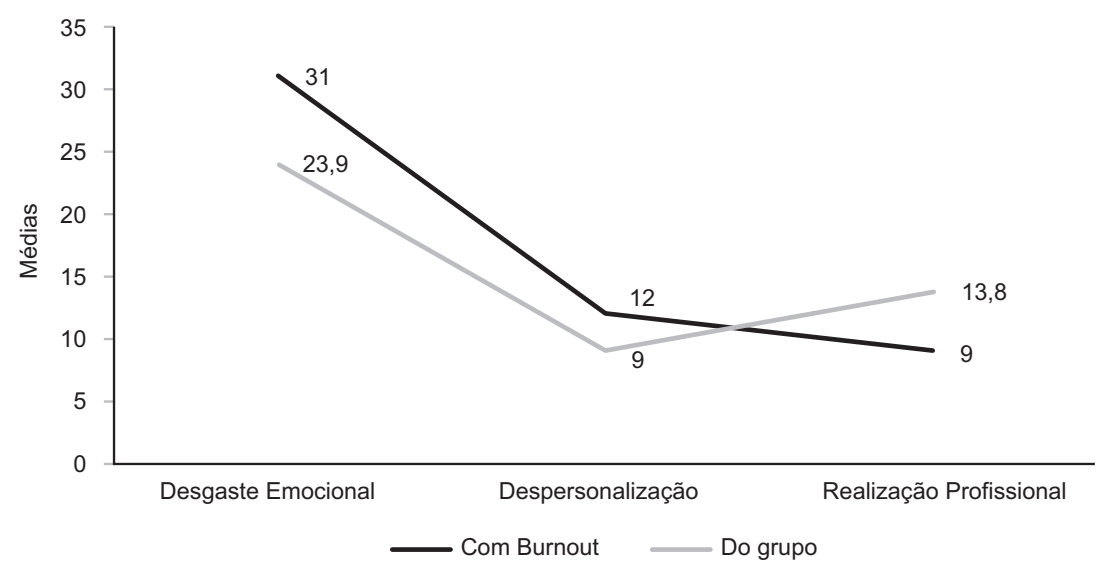

Figura 1 - Distribuição das médias dos trabalhadores da Estratégia de Saúde da Família no Maslach Burnout Inventory e do grupo com Burnout - Santa Maria - 2007

$\mathrm{O} \mathrm{MBI}$ foi validado com enfermeiras que trabalham em hospital, o que exigiu a realização do teste Alpha de Cronbach para avaliar sua consistência interna com trabalhadores da ESF, pois esta medida avalia a variabilidade das respostas. $O$ valor do conjunto de respostas foi de 0,879 e demonstrou que o instrumento tem boa confiabilidade para este grupo.

Comparando os valores do Alpha de Cronbach do Inventário com os de outros estudos ${ }^{(1-2)}$ que utilizaram o mesmo instrumento, verificou-se o mesmo comportamento, ou seja, a subescala de desgaste emocional apresenta a maior confiabilidade, seguido da realização profissional e da despersonalização.

\section{DISCUSSÃO}

No Brasil, a Síndrome de Burnout consta na Regulamentação da Previdência Social, em seu Anexo II, que trata dos Agentes Patogênicos causadores de Doenças Trabalhadores, sob o número $304848 / 99^{(14)}$. No Código Internacional de Doenças (CID-10) ${ }^{(15)}$, aparece de forma genérica no código Z73.0 do Capítulo XXI que trata dos Fatores que influenciam o estado de saúde e o contato com os serviços de saúde, e é entendida como esgotamento.

A Síndrome é caracterizada pela auto percepção de desgaste emocional, despersonalização e falta de realização profissional do indivíduo ${ }^{(6,9)}$.
O desgaste emocional se refere à sensação de esgotamento físico e mental, aos sentimentos de falta de energia para as atividades diárias, ou seja, de haver chegado ao limite das forças. A despersonalização indica que o indivíduo vem alterando seus sentimentos e comportamentos, tornando-se frio e impessoal com os usuários e colegas e, por vezes, cínico e irônico em relação às pessoas e situações. E a falta de realização profissional ou incompetência profissional se refere aos sentimentos de insatisfação, baixa auto-estima, sensação de fracasso profissional e desmotivação com as atividades laborais ${ }^{(13)}$.

A prevalência desta Síndrome esta entre trabalhadores jovens, sendo mais comum entre os que ainda não alcançaram 30 anos $^{(6,11-12)}$; e é atribuída a pouca experiência do trabalhador, a qual acarreta insegurança, ou choque com a realidade quando este percebe que o trabalho não garantirá a realização de suas ansiedades e desejos. A idealização, comum entre jovens trabalhadores, associa-se a expectativas elevadas, que muitas vezes não são concretizadas. Logo, a excessiva motivação, paradoxalmente, torna os indivíduos mais vulneráveis à Síndrome de Burnout $^{(6,16)}$. Na presente pesquisa verificou-se que o grupo mais jovem, com idade entre 20 e 40 anos obtiveram escores com diferença estatística significativa em desgaste emocional e despersonalização, quando comparados com outras faixas etárias. 
Em relação ao sexo, prevaleceu o feminino $(84,9 \%)$ e não se encontrou correlação desta variável com a Síndrome de Burnout. Algumas pesquisas apresentam pontuações mais elevadas em desgaste emocional entre as mulheres e em despersonalização entre os homens, o que é atribuído a influência dos papéis sociais ${ }^{(7,13)}$. No caso das mulheres, o desgaste emocional pode ser decorrente da dupla jornada de trabalho (cuidados do lar e desempenho profissional), comumente adotada por elas. E a despersonalização estaria associada aos homens em decorrência da pressão e exigência social em relação ao cumprimento de determinados papéis masculinos. A literatura também apresenta controvérsia quanto à associação entre a variável ter filhos e a Síndrome de Burnout ${ }^{(6,9,11,16)}$. Algumas investigações inferem que a paternidade gera pressão devido à carga que o sujeito passa a assumir, enquanto outras referem que o fato de ter filhos equilibra o indivíduo e possibilita o uso de meIhores estratégias de enfrentamento das situações problemáticas. Este comportamento é atribuído à maior cobrança do indivíduo que, com o nascimento dos filhos, se torna responsável por outro e, dessa forma, necessita adotar condutas seguras e evitar comportamentos de risco ${ }^{(6)}$.

Neste estudo o sexo, o fato de ter filhos $(69,4 \%)$ ou ter companheiro $(68,2 \%)$ não teve associação estatística com a Síndrome. Igualmente, a média dos anos de escolaridade entre os trabalhadores $(14,4 \pm 4,9)$ não apresentou associação com as sub escalas do MBI. No entanto, alguns pesquisadores descrevem que os indivíduos com maior escolaridade tendem a apresentar escores mais elevados nas dimensões desgaste emocional e despersonalização e mais baixos em realização pessoal no trabalho, o que pode estar relacionado à falta de reconhecimento e status de algumas profissões ${ }^{(11)}$.

Outras variáveis do trabalho associadas ao Burnout em algumas investigações são o tempo de trabalho e o tempo na profissão. Estes estudos apontam que a Síndrome de Burnout pode ter início no primeiro ano que o indivíduo ingressa na instituição de trabalho. É atribuída às dificuldades do trabalhador para sua inserção no grupo, para execução das tarefas, ao sentimento de instabilidade no emprego associada à necessidade de aceitação e reconhecimento, entre outros aspectos ${ }^{(17)}$. Cabe lembrar que os estudos divergem, ora apontam que a incidência da Síndrome de Burnout aumenta com o tempo de trabalho, ora acomete os ingressantes no mercado de trabalho, devido a pouca experiência na profissão e/ou na instituição ${ }^{(6,12)}$.

Ao iniciar na ESF é recomendado que os trabalhadores recebam treinamento para atuarem em consonância com esta modalidade de atenção do Sistema Único de Saúde (SUS). O perfil inadequado dos trabalhadores, o exacerbo de cooperativismos, a falta de capacitação, a remuneração insuficiente e a ausência de uma política de recursos humanos, além de impedirem a construção de um sistema de saúde universal, integral e equânime ${ }^{(18)}$, podem gerar frustração profissional ao trabalhador.

A Estratégia requer dedicação exclusiva dos trabalhadores, exige a disponibilidade de 40 horas semanais, ou seja, 8 horas diárias; e a ESF como único vínculo empregatício. Nesse sentido, faz-se necessário comentar sobre o percentual de trabalhadores da ESF que trabalha em outro local $(32,6 \%)$, na maioria das vezes nos turnos da noite, dado encontrado na primeira parte do Inventário de Burnout de Maslach, a qual questionava os dados demográficos dos participantes. Pode-se inferir que isso se deve à necessidade de aumentar a renda familiar; prática comum entre os trabalhadores de saúde. Entre os médicos, muitos optam por se dedicarem além do atendimento na unidade básica, também ao consultório particular ou hospital, devido à flexibilidade de horários. O fato dos trabalhadores de saúde terem mais de um vínculo empregatício, se por um lado complementa a renda familiar, muitas vezes afeta o comprometimento com as atividades laborais ${ }^{(12,18)}$ devido ao cansaço que gera.

Analisando as atividades extralaborais realizadas pelos sujeitos do estudo, observou-se que, contraditoriamente, os trabalhadores de saúde, que conhecem os inúmeros benefícios da atividade física regular, não a desenvolvem. Cabe destacar a realização de atividades que produzem momentos de descontração e prazer, podem absorver o impacto de agentes estressores ${ }^{(16)}$.

O desenvolvimento da Síndrome de Burnout é multicausal e envolve vários fatores individuais e laborais, no qual as variáveis socioambientais são coadjuvantes do processo. O Inventário de Burnout procura identificar aspectos associados às relações e condições do trabalho que desencadeiam a síndrome, avaliando as dimensões desgaste emocional, despersonalização e os sentimentos de realização profissional(19).

\section{CONSIDERAÇÕES FINAIS}

Este estudo revelou que na realidade laboral da ESF de Santa Maria atuam trabalhadores de diferentes categorias profissionais e características sócio demográficas, que se destacam como sujeitos singulares e avaliam o trabalho como fonte de satisfação/insatisfação e prazer/sofrimento.

Ao investigar o estresse laboral vivenciado pelos trabaIhadores das equipes da ESF de Santa Maria, se identificou que $93,03 \%$ não apresentaram escores compatíveis com Burnout no MBI. No entanto o estudo apontou seis $(6,97 \%)$ participantes acometidos pela Síndrome de Burnout, sendo a idade jovem (até 40 anos) a única variável com associação estatística significativa com a Síndrome $(p=0,034)$. Observouse que a Síndrome de Burnout acometeu diferentes trabaIhadores, independente de sua formação, sexo ou função, não sendo exclusiva de uma categoria, mas com predominância entre os ACS (10,34\%) quando comparados com o grupo de profissionais (5,26\%) Acredita-se que pela pouca experiência, os indivíduos mais jovens possuem insegurança em relação ao trabalho e, por vezes, percebem que o mesmo não garantirá a realização de suas ansiedades e desejos, gerando insatisfação e desgaste ao trabalhador. 
Deste modo, cabe analisar a forma como ocorre a inserção dos trabalhadores jovens no meio laboral e o suporte social que recebem. Pois afora os danos à saúde, os trabalhadores com Burnout podem influenciar o trabalho da equipe interdisciplinar e comprometer a qualidade do trabalho, pois alguns são profissionais que por vezes atuam sozinhos e, no caso do médico e do enfermeiro, são os líderes da equipe.

Apesar das limitações do estudo, como o número limitado de trabalhadores, os dados desta investigação evidenciam a necessidade de detectar precocemente os problemas associados ao trabalho que possam gerar a Síndrome de Burnout em alguns indivíduos, bem como instaurar ações preventivas e interventivas, a fim de amenizar o desgaste do trabalhador. Portanto é preciso investir tanto as estratégias organizacionais como os programas de promoção da saúde entre os trabalhadores da ESF, visando melhorias no ambiente de trabalho, na estrutura dos serviços públicos e adoção de medidas voltadas para o fortalecimento das relações sociais de apoio à equipe.

A prevenção do estresse e da Síndrome de Burnout exige a reformulação dos mecanismos individuais e coletivos dos trabalhadores e muitas vezes envolvem a redefinição de conceitos e valores. Para tanto, algumas investigações ${ }^{(6,9-10,18,20)}$ sinalizam as relações interpessoais e o apoio do grupo de trabalho como estratégia para minimizar os efeitos nocivos do trabalho à saúde do trabalhador e recomendam ações que valorizem o sujeito. Portanto a prevenção da Síndrome de Burnout requer ações educativas e terapêuticas nos planos individual, grupal, social e organizacional(20).

Ressalta-se que as questões que afetam a saúde do trabalhador necessitam ampla discussão nos ambientes de trabalho e nos espaços de formação profissional. Acreditase que desta forma possam contribuir a saúde ocupacional, bem como favorecer que as relações que se processam entre trabalho e trabalhador sejam harmoniosas e revestidas de proteção(2).

Por fim, sugere-se a criação de programas de apoio social, de aprimoramento do trabalho em equipe, planejamento dos serviços com auxílio dos membros das equipes, para favorecer o crescimento pessoal e profissional dos mesmos, favorecer a qualidade dos serviços públicos e prevenir o estresse laboral.

\section{REFERÊNCIAS}

1. Azambuja EP, Kerber NPC, Kirchhof AL. A saúde do trabalhador na concepção de acadêmicos de enfermagem. Rev Esc Enferm USP. 2007;41(3):355-62.

2. Lautert L. O Processo de enfrentamento do estresse no trabaIho hospitalar: um estudo com enfermeiras. In: Haag GS, Lopes MJM, Schuck JS. A enfermagem e a saúde dos trabalhadores. Goiânia: AB; 2001. p. 114-40.

3. Camelo SHH, Angerami ELS. Sintomas de estresse nos trabaIhadores atuantes em cinco núcleos de saúde da família. Rev Lat Am Enferm. 2004;12(1):14-21.

4. Brasil. Ministério da Saúde. Programa de Saúde da Família. Brasília; 2001.

5. Bianchi ER. Estresse em enfermagem: análise da atuação do enfermeiro em Centro Cirúrgico [tese]. São Paulo: Escola de Enfermagem, Universidade de São Paulo; 1990.

6. Benevides-Pereira AMT. Burnout: quando o trabalho ameaça o bem-estar do trabalhador. São Paulo: Casa do Psicólogo; 2002.

7. Lipp MEN. Inventário de sintomas de stress para adultos de LIPP (ISSL). São Paulo: Casa do Psicólogo; 2000.

8. Costa JRA, Lima JV, Almeida PC. Stress no trabalho do enfermeiro. Rev Esc Enferm USP. 2003;37(3):63-71.

9. França HH. A Síndrome de Burnout. Rev Bras Med. 1977;44 (8):197-99.

10. Dejours C. A banalização da injustiça social. Rio de Janeiro: FGV; 2006.
11. Beltrán CA. Factores psicosociales y Síndrome de Burnout en médicos de familia. An Faculdad Med. 2005;(3):225-31.

12. Maslach C, Schaufeli WB, Leiter MP. Job Burnout. Ann Rev Psycol. 2001;52:397-422.

13. Lautert L. O desgaste profissional do enfermeiro [tese]. Salamanca: Faculdade de Psicologia, Universidade Pontifícia de Salamanca; 1995.

14. Brasil. Decreto n. 3.048/99, de 6 de maio de 1996. Dispõe sobre a regulamentação da Previdência Social e dá outras providências. Diário Oficial da União, Brasília, 7 maio 1999.

15. Organização Mundial da Saúde. Classificação de Doenças e problemas relacionados à Saúde. São Paulo: Centro Colaborador da OMS para Classificação de Doenças em Português; 1993.

16. Carlotto MS. Síndrome de Burnout: um tipo de estresse ocupacional. Canoas: ULBRA; 2001.

17. Freudenberger HJ. Staff burn-out. J Soc Issues. 1974;30:159-65.

18. Borges LO, Tamayo A, Alves Filho A. Significado do trabalho entre trabalhadores de saúde. In: Borges LO. Os trabalhadores de saúde e seu trabalho. São Paulo: Casa do Psicólogo; 2005. p. 143-98.

19. Maslach C, Jackson S. The measurement of experienced Burnout. J Occup Behav. 1981;2(1):99-113.

20. Trindade LL. O estresse laboral da equipe de saúde da família: implicações para saúde do trabalhador [dissertação]. Porto Alegre: Escola de Enfermagem, Universidade Federal do Rio Grande do Sul; 2007. 